\title{
Upper limb function in persons with long term paraplegia and implications for independence: Part II
}

\author{
WE Pentland PhD, ${ }^{1}$ LT Twomey $\mathrm{PhD}^{2}$ \\ ${ }^{1}$ Assistant Professor of Occupational Therapy, School of Rehabilitation Therapy, Queen's \\ University, Kingston, Canada; ${ }^{2}$ Professor of Physiotherapy and Deputy Vice-Chancellor, \\ Curtin University, Perth, Western Australia.
}

\begin{abstract}
Research has shown that wheelchair use in long term paraplegia is associated with upper limb pain and degeneration that interferes with the independent performance of activities of daily living. This paper proposes a model to explain the development of upper limb problems in persons with long term paraplegia, and one that will guide in the prevention and management of this type of long term complication.
\end{abstract}

Keywords: paraplegia; activites of daily living; aging; upper extremity function.

\section{Introduction}

Improvements in technology and health care have increased the life expectancy of persons sustaining a major spinal cord injury (SCI). The life expectancy of persons with paraplegia is now close to that of the able bodied population. ${ }^{1}$ Society's improved awareness of the capabilities and needs of persons with disabilities has removed many physical and attitudinal barriers and has in turn often created new expectations for this group. More options are now available, and persons with paraplegia achieve independent and very active life roles including employer, employee, parent, homemaker, and athlete. Maintenance of the high levels of independence normally attained by persons with SCI hinges on the integrity of their upper limbs. Life in a wheelchair, including wheeling and repeated lifting of body weight during transfers, places great demands on the bones, joints, and soft tissues of the upper extremities that exceed those on able bodied persons. The focus of rehabilitation and research has traditionally been on the acute, restorative, and early postdischarge phases of care. Now, as more persons with paraplegia are surviving into later life, a new set of problens has arisen as aging is superimposed on preexisting disability.

Occupational and sport related overuse conditions in the able bodied population have received considerable attention in the literature. But only a few studies have examined changes in arm function and the development of overuse related upper limb pathology in long term wheelchair and crutch users. The research to date suggests that mobility aid users are predisposed to developing upper exremity pain and pathology over time. Table I summarizes that literature.

\section{Methods}

In addition to pain prevalence, it is important to determine the impact of upper limb problems on daily function. In our study of 52 persons with paraplegia (mean age 44 years; mean duration of SCI 17 years) we asked subjects when the upper limb pain occurred..$^{11}$ A very high prevalence $(60 \%)$ of upper limb pain was reported by the SCI group. The tasks most commonly reported to elicit upper limb pain (work/school, transfers, outdoor wheeling, driving) are also the activities that allow interaction in the community and are associated with roles that are important for independence and self esteem. Clearly, it is important to minimize the development of upper limb problems in the wheelchair user; both for the individual's comfort and quality of life, and to minimize lost productivity and increased health and support care costs to society. 
Table 1 Reported prevalences of upper limb pain in subjects with SCI (post rehabilitation)

\begin{tabular}{|c|c|c|c|c|c|}
\hline \multirow[t]{2}{*}{ Authors } & \multirow[t]{2}{*}{ Sample } & \multirow[t]{2}{*}{ No. } & \multicolumn{3}{|c|}{ Pain prevalence } \\
\hline & & & Shoulder & Elbow & Wrist/Hand \\
\hline Nichols et $a l^{2}$ & SCI & 517 & $54 \%$ & & \\
\hline Blankstein et $\mathrm{l}^{3}$ & Wheelchair \& crutch users & 50 & $38 \%$ & $32 \%$ & $48 \%$ \\
\hline Aljure et $a l^{4}$ & Paraplegia & 47 & & & $63 \%$ \\
\hline Bayley et $a l^{5}$ & SCI & 94 & $30 \%$ & & \\
\hline Tun \& Upton ${ }^{6}$ & Paraplegia & 60 & & & $37 \%$ \\
\hline Gellman et $\mathrm{al}^{7}$ & Paraplegia & 84 & $35 \%$ & $4 \%$ & $9 \%$ \\
\hline Gellman et al ${ }^{8}$ & Paraplegia & 77 & & & $49 \%$ \\
\hline Pentland \& Twomey ${ }^{9}$ & Paraplegia & $\begin{array}{c}11 \\
\text { (female) }\end{array}$ & $39 \%$ & $31 \%$ & $45 \%$ \\
\hline Sie et $a l^{10}$ & Quadriplegia & 136 & $46 \%$ & $15 \%$ & $15 \%$ \\
\hline Sie et al ${ }^{10}$ & Paraplegia & 103 & $36 \%$ & $16 \%$ & $13 \%$ \\
\hline Pentland \& Twomey ${ }^{11}$ & Paraplegia & 52 & $39 \%$ & $31 \%$ & $40 \%$ \\
\hline
\end{tabular}

In order to know how and where to intervene, we need to understand how, why, and when upper limb problems seem to develop in this population. Based on our work, there appear to be a number of key factors that interact in the development of upper limb problems in persons with paraplegia (Fig 1).

The individual's physical predisposition to upper limb overuse problems

The performance of daily living activities while in a wheechair can place significant stresses on the upper limbs. If the integrity of the upper limbs is already compromised by previous trauma, preexisting disease, muscle imbalance, or congenital musculoskeletal anomalies, then superimposing the additional stresses of wheelchair use may increase the risk of developing overuse related problems.

\section{Behaviour and lifestyle}

Unlike the lower limbs, the upper were designed for mobility, at the expense of stability. ${ }^{12}$ Wheelchair use places significant

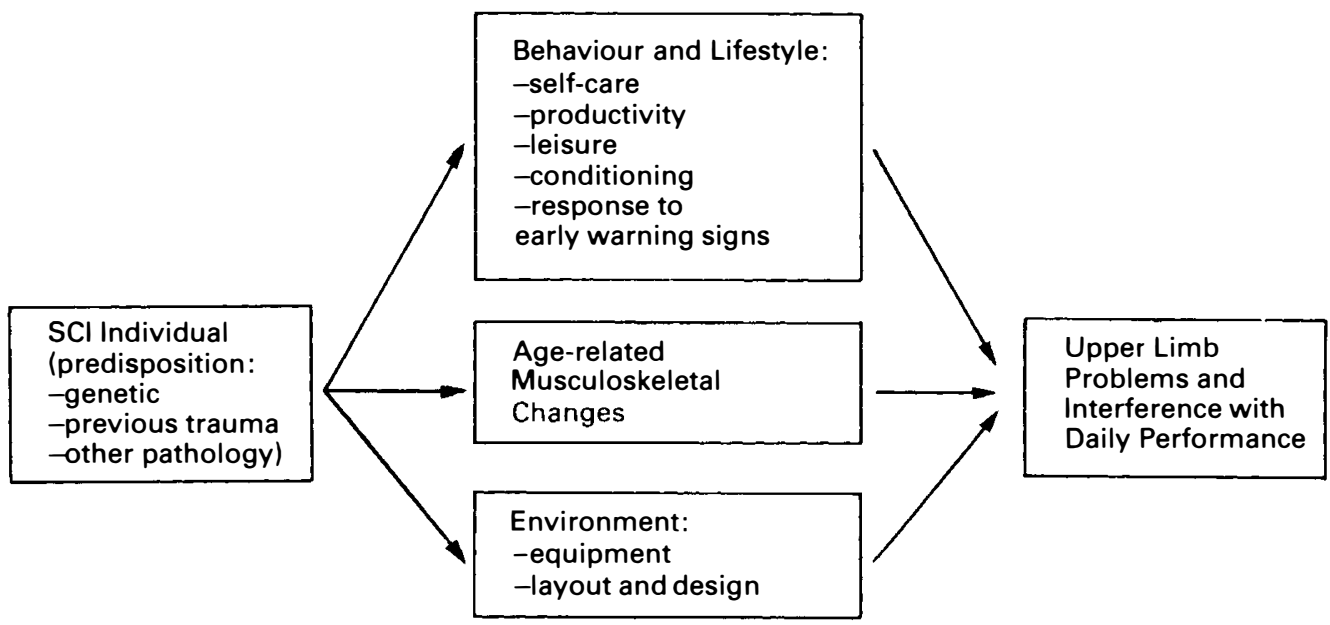

Figure 1 The development of overuse related upper limb problems in individuals with spinal cord injury. 
stability and mobility demands on the upper limbs. To date there has been very little research on the biomechanics and kinematics of wheelchair activities, other than in elite wheelchair athletes.

The musculoskeletal system can adapt to stresses, and indeed moderate stresses are essential to stimulate and maintain its integrity (e.g. increased muscle strength or endurance; higher bone density; enhanced articular cartilage nutrition, metabolic activity and healing; improved tendon and ligament resilience). But periods of unusually high or long activity or stresses in ranges to which the tissues are unaccustomed will cause damage. Without rest and healing, this injury can become chronic. Some studies have attempted to determine the effects of different types of stress on the upper limbs. Articular cartilage has been shown to be fairly resistant to rubbing, but is vulnerable to repetitive impulse loading. ${ }^{13}$ In the industrial and sports overuse literature, the most common kinematic culprit causing overuse seems to be repetitive movements, sometimes in the magnitude of 25,000 repetitions per day on an assembly line, and vibration stresses from hand held power equipment. Neither of these are normally inherent in wheelchair use. What are inherent seem to be stresses either of a magnitude or in a range for which the upper limb is untrained.

The main factors precipitating overuse in the shoulder appear to be: (1) rotator cuff compression and muscle fatigue resulting from repetitive or static shoulder elevation; ${ }^{14-16}$ (2) work posture $;^{17,18}$ (3) chronological age: ${ }^{19,20}$ and (4) compression and ischaemia within the shoulder joint region due to weight-bearing on the shoulder. ${ }^{5,21}$ Wheelchair transfers involve weight-bearing and compression in the shoulder joint. ${ }^{5}$ Since environments are designed primarily for the able bodied, the wheelchair user must frequently reach up and therefore work in shoulder elevation. The forces borne by the glenohumeral joint during elevation activities are often underestimated. Poppen \& Walker ${ }^{22}$ calculated the resultant forces at $90^{\circ}$ shoulder abduction to be 0.89 times body weight. Observation of wheeling techniques reveal the shoulders are often held in close to $40^{\circ}$ abduction during the initial push phase. By $45^{\circ}$ of shoulder abduction, there is already tendon compression of subscapularis, supraspinatus, and some infraspinatus and by $90^{\circ}$ of abduction, there is compression of all four rotator cuff tendons. ${ }^{23}$

Behaviour and lifestyle of the wheelchair user will play a role in whether overuse problems develop. The musculoskeletal stresses inherent in different roles vary tremendously, for example, among the wheelchair user with a sedentary desk job, the elite athlete, or the homemaker caring for young children. Even if the individual engages in a more stressful activity, how he or she paces that activity and responds to injuries, fatigue, and early warning signs of overuse, will be significant determinants of whether overuse problems develop and whether they become chronic.

What seems to be important is maintaining conditioning levels that are suitable for what the individual wants to do, environments and equipment that do not require unusual or sudden loading, careful progression of activity intensity, and rest and attention at early warning signs of pain or problems.

\section{Age-related changes in the musculoskeletal system}

It is generally well accepted that there are age-related declines in the musculoskeletal system. Therefore the wheelchair user may find that some activities become more difficult or impossible, the risk of injury increases, and the importance of maintaining condition is highlighted. For the wheelchair user who already experiences upper limb overuse problems, age-related declines in function can be more devastating.

In the general population, there are relatively small strength losses with age until the sixth or seventh decade $(<20 \%){ }^{24}$ Strength losses then accelerate beyond the seventh decade. However, strength is trainable until very late in life, and activity and conditioning can help to offset age-related strength losses. Articular cartilage (AC) also deteriorates over time; however, it is not clear to what extent the phenomena of aging, 
wear and tear, and osteoarthritis (OA) are discrete or interactive processes. The effects of aging on AC become evident in the third decade, increase slowly until the fifth, and then become rapid so that they are very common in those over 70 years of age. ${ }^{25.26}$ The process appears to proceed at different rates in different joints, with the shoulder showing relatively early degenerative signs. Age-related AC changes include thinning, decreased tensile strength, roughening, and increased joint congruity. This increase in congruity is seen as undesirable since some incongruity is necessary for the mechanics of synovial fluid circulation and hence adequate cartilage nutrition. ${ }^{27,28}$

Age-related declines in the musculoskeletal system will interact with the wheelchair user's past and present behaviour and lifesyle as well as with his or her predisposing characteristics (previous upper limb trauma, joint abnormalities, disease such as rheumatoid arthritis) and may significantly exacerbate the development of overuse problems. But it is important to recognize that the maintenance of good physical condition can be of significant benefit in offsetting age-related declines. In addition, modifying ADL techniques or the environment and assistive devices can eliminate sudden, unusual, or heavy stress on the upper limbs.

\section{Environment}

The environment and assistive device design and availability are critical variables in moderating the effects of predisposing characteristics, behaviour, and aging on the integrity of the wheelchair user's upper limbs and independent function. Ergonomically designed environments and assistive devices can ensure that the wheelchair user's upper limbs are functioning in postures that take advantage of strength and joint stability. Unnecessary repetitive motions, awkward or static body positions, and heavy impulse loadings can be avoided. Shoulder elevation and abduction, particularly under load, can be minimized. Good trunk posture can be facilitaed. The opportunity to vary technique and avoid repetitive stresses can be provided. In those with existing overuse problems, painful or exacerbating tasks can be modified, assisted, or perhaps eliminated. Energy can be saved and stresses minimized through work simplification strategies and attention to features such as wheeling surfaces, storage design, and work areas. ${ }^{29}$

More research is needed that examines the biomechanics and kinematics of daily wheelchair activities. This will give a basis on which to better design and develop suitable environments and assistive devices for the wheelchair user.

\section{Conclusions}

Based on our research, upper limb pain that interferes with daily function does tend to occur over time in persons with paraplegia who use wheelchairs. This appears to be due to an interaction of four general factors: (1) the SCI individual's physical predisposition to upper limb overuse; (2) his or her behaviour and lifestyle; (3) age-related changes in the musculoskeletal system; and (4) the environment in which the individual must function. These findings have numerous implications for the spinal cord injured, and the broad range of disciplines who work with this population.

Persons with paraplegia need to realize the importance of respecting and protecting their upper limbs as an essential resource to their continued independence. Persons who use wheelchairs should be educated regarding joint protection and upper exremity conditioning techniques, including strengthening and flexibility programs. They need to be educated about the importance of warming up before stressing the upper limbs, including, for example, before the first transfer out of bed in the morning. They also need to understand that musculoskeletal training benefits are limited to the range of motions within which the training took place. Therefore, they must exercise caution and avoid sudden or unusual stresses for which their arms are not conditioned, such as toilet transfers in inaccessible washrooms, or long distance pushes which they have not trained for gradually. They need to be encouraged to consult with health care service providers as soon as pain or overuse 
problems begin. Problem solving and treatment strategies will have a greater chance of being effective if begun early. Early identification of overuse problems may allow intervention before the condition becomes chronic.

Coaches and trainers need to understand the importance of ensuring that wheelchair using athletes progress their training appropriately. Unlike the able bodied athlete, lower limb disabled athletes cannot easily rest the upper limbs after a training session. This creates fertile ground for overuse injuries.

Service delivery planners and those who determine insurance settlements need to consider that upper limb pain and weakness, and subsequent difficulties with the independent performance of ADL should be expected to develop in this population, and that the onset appears often to occur 10-15 years after the SCI or sooner.

For persons who use a wheelchair, it is important to ensure the availability of appropriate assistive devices. Of particular importance are ergonomically designed personal and public environments that minimize the stresses on the upper limbs, with features such as lowered work and storage surfaces, and barrier-free entrances and facilities. There is a need to educate persons with paraplegia as to work simplification and alternative ADL methods so that they can reduce heavy or repetitive stresses on their upper limbs. The skills to perform a variety of transfer, and even propulsion, techniques would enable a person not only to avoid problems associated with repetitive use, but also to devise safe movements when in an unfamiliar environment, and to be able to alternate techniques if early signs of overuse occur.

Clinically, these results point to the need to monitor persons with paraplegia regardless of their age, for the development of overuse pathology in the upper limbs. If the upper limbs of those with paraplegia are prone to the development of overuse problems, then the wheelchair user whose upper extremities are already compromised by weakness and muscle imbalance (e.g. quadriplegia, poliomyelitis, degenerative neurological conditions) may be especially at risk.

Further research needed in this area includes information that will add to the understanding of the kinematics and biomechanics of wheelchair use by the typical user (as opposed to the elite athlete) and the effect of posture, positioning, environment, and assistive devices for moderating stresses in the upper limbs. There is a need for the implemetation and evaluation of upper limb overuse prevention and management programs for persons who use wheelchairs. There is also a need for more research that examines changes with age in persons with severe disability; physically, functionally, and psychosocially.

\section{Acknowledgements}

This paper is based on a presentation at the Ninth International Seating Symposium in Memphis, Tennessee, February 1993. The research on which this paper is based was supported by the Rick Hansen Man in Motion Legacy Fund, the Ontario Ministry of Health, and the Queensland Federation of University Women. The support of these agencies is gratefully acknowledged.

\section{References}

1 Trieschmann R (1987) Spinal Cord Injuries: Psychological, Social, and Vocational Rehabilitation. Demos, New York.

2 Nichols P, Norman P, Ennis J (1979) Wheelchair users shoulder? Scand J Rehabil Med 11: $29-32$.

3 Blankstein A, Shmuelie R, Wingarten I, Engel J, Ohry A (1985) Hand problems due to prolonged use of crutches and wheelchair. Orthop Rev 14: 29-34.

4 Aljure J, Eltorai I, Bradley W, Lin J, Johnson B (1985) Carpal tunnel syndrome in paraplegic patients. Paraplegia 23: 182-186.

5 Bayley J, Cochrane T, Sledge C (1987) The weight-bearing shoulder. J Bone Joint Surg 69: 676-678.

6 Tun C, Upton J (1988) The paraplegic hand: Electrodiagnostic studies and clinical findings. J Hand Surg 13: 716-719. 
7 Gellman H, Chandler D, Petrasek J, Sie I, Adkins R, Waters R (1988) Carpal tunnel syndrome in paraplegic patients. J Bone Joint Surg 70A: 517-519.

8 Gellman H, Sie I, Waters R (1988) Late complications of the weight-bearing upper extremity in the paraplegic patient. Clin Orthop 238: 132-135.

9 Pentland W, Twomey LT (1994) Upper extremity function in long term paraplegia and implications for independence: Part I. Paraplegia 32: 211-218.

10 Sie IH, Waters RL, Adkins RH, Gellman H (1992) Upper extremity pain in the post-rehabilitaion spinal cord injured patient. Arch Phys Med Rehabil 73: 44-48.

11 Pentland W, Twomey LT (1991) The weight-bearing upper extremity in women with longterm paraplegia. Paraplegia 29: 521-530.

12 Sarrafian S (1983) Gross and functional anatomy of the shoulder. Clin Orthop 173: 11-19.

13 Radin EL, Paul IL (1971) Response of joints to impact loading 1. In vitro wear. Arthritis Rheum 14: 356-362.

14 Hawkins RJ, Kennedy JC (1980) Impingement syndrome in athletes. Am J Sports Med 8: 151-158.

15 Neer CS (1972) Anterior acromioplasty for the chronic impingement syndrome in the shoulder. J Bone Joint Surg 54A: 41-50.

16 Herberts P, Kadefors R, Hogfors C, Sighom G (1984) Shoulder pain and heavy manual labour. Clin Orthop 191: 166-178.

17 Neviaser RJ (1983) Painful conditions affecting the shoulder. Clin Orthop 173: 63-69.

18 Punnett L (1987) Upper extremity musculoskeletal disorders in hospital workers. J Hand Surg 12: 858-862.

19 Westerling D, Jonson BG (1980) Pain from the neck-shoulder region and sick leave. Scand J Doc Med 8: 131-136.

20 Buckle P (1987) Musculoskeletal disorders of the upper exremities. J Hand Surg 12: 885-889.

21 Pringle RG (1984) Crutchwalker's shoulder. In: Bateman JE, Walsh RP, editors. Surgery of the Shoulder. BC Decker, Philadelphia: 324-325.

22 Poppen PS, Walker NK (1978) Forces in the glenolumeral joint in abduction. Clin Orthop 135: 165-170.

23 Nasca RJ, Salter EC, Weil CE (1984) Contact areas of the 'subacromial' joint. In: Bateman JE, Welsh RP, editors. Surgery of the Shoulder. C V Mosby, Toronto: 134-139.

24 Vandervoort AA, Hayes KC, Belanger AY (1986) Strength and endurance of skeletal muscle in the elderly. Physiotherapy Canada 38: 167-173.

25 Eyanson S, Brandt KD (1984) Osteoarthritis. Prim Care 11: 259-269.

26 Peyron JG (1987) Risk factors in osteoarhritis - How do they work? J Rheumatol 14: 1-2.

27 Brandt KD (1988) Osteoarthritis. Clin Geriatr Med 4: 279-293.

28 Bullough PG (1981) The geometry of diarthrodial joints, its physiologic maintenance, and the possible significance of age-related changes in geometry-to-load distribution and the development of osteoarthritis. Clin Orthop 156: 61-66.

29 Wolfe G (1978) Influence of floor surface on energy cost of wheelchair propulsion. Orthop Clin North Am 9: $367-377$. 